\title{
An expert opinion of the Polish Cardiac Society Working Group on Pulmonary Circulation and the Polish Society for Rheumatology on the diagnosis and treatment of pulmonary hypertension in patients with connective tissue disease
}

\author{
Tatiana Mularek-Kubzdela', Michał Ciurzyński², Otylia Kowal-Bielecka³, Jarosław D Kasprzak4, Grzegorz Kopećs, \\ Katarzyna Mizia-Stec ${ }^{6}$, Ewa Mroczek , Ewa Lewicka ${ }^{8}$, Ilona Skoczylas ${ }^{9}$, Marek Grabka ${ }^{10}$, Michał Furdal'1", \\ Michał Florczyk ${ }^{12}$, Marek Brzosko'33, Bogdan Batko ${ }^{14}$, Hanna Przepiera-Będzak ${ }^{13}$, Włodzimierz Samborski15, \\ Eugeniusz J Kucharz ${ }^{16}$
}

Reviewers: Adam Torbicki ${ }^{17}$, Piotr Wiland ${ }^{18}$

\begin{abstract}
'Department of Cardiology, Karol Marcinkowski Medical University, Poznań, Poland
2Department of Internal Medicine and Cardiology, Medical University of Warsaw, Warszawa, Poland

${ }^{3}$ Department of Rheumatology and Internal Medicine, Medical University of Bialystok, Białystok, Poland

${ }^{4}$ Department of Cardiology, Medical University of Lodz, Bieganski Regional Specialist Hospital, Łódź, Poland

${ }^{5}$ Pulmonary Circulation Center, Department of Cardiovascular Diseases, Jagiellonian University Collegium Medicum, John Paul II Hospital in Krakow, Kraków, Poland

${ }^{6}$ Department of Cardiology, Medical Faculty in Katowice, Medical University of Silesia, Katowice, Poland

${ }^{7}$ Cardiology Department, Regional Hospital in Wrocław, Research and Development Center, Wrocław, Poland

${ }^{8}$ Department of Cardiology and Electrotherapy, Medical University of Gdansk, Gdańsk, Poland

${ }_{9}^{9}{ }^{\text {rd }}$ Department of Cardiology, Faculty of Medical Sciences in Zabrze, Medical University of Silesia, Katowice, Poland

${ }^{10} 1^{\text {st }}$ Department of Cardiology Silesian University of Medicine Katowice, Katowice, Poland

${ }^{11}$ Cardiology Department, Centre for Heart Diseases, $4^{\text {th }}$ Military Hospital, Wrocław, Poland

${ }^{12}$ Department of Pulmonary Circulation, Thromboembolic Diseases and Cardiology, Centre of Postgraduate Medical Education, European Health Center Otwock, Otwock, Poland

${ }^{13}$ Department of Rheumatology, Internal Medicine, Geriatrics and Clinical Immunology, Pomeranian Medical University, Szczecin, Poland

${ }^{14}$ Department of Rheumatology and Immunology, A.F. Modrzewski University, Kraków, Poland

${ }^{15}$ Department of Rheumatology, Rehabilitation and Internal Medicine, Karol Marcinkowski Medical University, Poznań, Poland

${ }^{16}$ Department of Internal Medicine, Rheumatology and Clinical Immunology, Medical University of Silesia, Katowice, Poland

${ }^{17}$ Centre of Postgraduate Medical Education, School of Medical Science, Otwock, Poland

${ }^{18}$ Department and Clinic of Rheumatology and Internal Diseases, Faculty of Medicine, Wroclaw Medical University, Wrocław, Poland
\end{abstract}

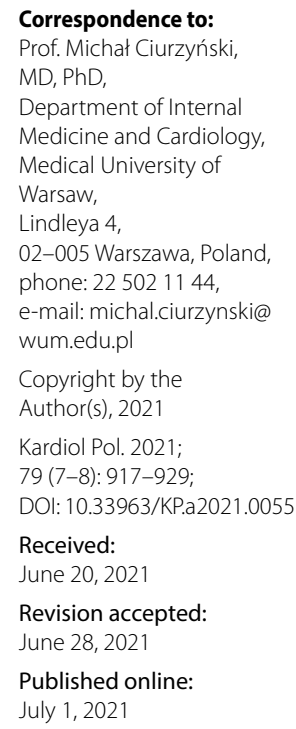

\section{A B STRACT}

Systemic connective tissue diseases (CTDs) comprise a large group of autoimmune diseases and are characterized by the involvement of multiple systems and organs. Pulmonary hypertension $(\mathrm{PH})$ of various etiologies may develop in the course of CTD, including pulmonary arterial hypertension (PAH), $\mathrm{PH}$ secondary to the lung disease, postcapillary $\mathrm{PH}$ in the course of left heart disease, and chronic thromboembolic pulmonary hypertension (CTEPH). In addition, the different forms of PH may coexist with each other. Among patients with CTD, PAH occurs most commonly in those with systemic sclerosis, where it affects approximately $8 \%-12 \%$ of patients. The prognosis in patients with untreated $\mathrm{PAH}$ is very poor. It is particularly important to identify the high-risk CTD-PAH population and to perform efficient and accurate diagnostics so that targeted therapy can be introduced. Echocardiography is used to screen for $\mathrm{PH}$, but clinical and echocardiographic suspicion of $\mathrm{PH}$ always requires confirmation by right heart catheterization. Confirmation of $\mathrm{PAH}$ enables the initiation of life-prolonging pharmacological treatment in this group of patients, which should be administered in referral centers. Drugs available for pharmacological management include endothelin receptor antagonists, phosphodiesterase- 5 inhibitors, and prostacyclins.

Key words: pulmonary hypertension, connective tissue disease, autoimmune disease, systemic sclerosis, systemic lupus erythematosus 


\section{INTRODUCTION}

Pulmonary hypertension ( $\mathrm{PH})$ is a clinical complication of systemic connective tissue diseases (CTDs), and its occurrence has a significant, negative prognostic value. The etiology of $\mathrm{PH}$ in patients with CTD is heterogeneous and includes: pulmonary arterial hypertension (CTD$\mathrm{PAH}$ ); pulmonary veno-occlusive disease (PVOD; a rare, fatal form of PAH caused by progressive blockage of the capillaries and small pulmonary veins); $\mathrm{PH}$ secondary to lung disease (primary cause: pulmonary fibrosis) and/or hypoxemia; postcapillary PH in the setting of cardiac disease (left ventricular systolic/diastolic dysfunction); and chronic thromboembolic PH (CTEPH) associated with hypercoagulability, e.g., antiphospholipid syndrome, or resulting from a history of pulmonary thromboembolic incidents. Furthermore, more than one etiologic factor may be important in the pathogenesis of CTD-PH, and the importance of individual etiologic factors may change during the course of the disease.

Given the potential for targeted therapy in $\mathrm{PAH}$, it is particularly important to identify the high-risk CTD-PAH population and to initiate treatment early. Mounting scientific evidence confirms that early implementation of targeted treatment significantly prolongs life in this group of patients. The tremendous variability of CTD is associated with different prevalences of PAH in different types of CTD. PAH is a relatively common complication of systemic sclerosis (SSc); it affects $8 \%-12 \%$ of SSc patients and is associated with approximately $30 \%$ of deaths in this population. In contrast, it is less common in patients with mixed connective tissue disease (MCTD) and systemic lupus erythematosus (SLE) [1].

Dyspnea, which is a key symptom of PAH in patients with CTD, can have a variety of causes, so early diagnosis of CTD-PAH presents diagnostic difficulties. Screening for CTD-PAH should therefore be carried out regardless of symptomatology - it requires an active, interdisciplinary approach with an emphasis on cooperation between rheumatologists, cardiologists, radiologists, and pulmonologists managing patients with CTD $[2,3]$.

The development of a common scheme of regular screening for PAH in patients with CTD which could be implemented in Poland is of considerable practical importance, especially considering that the percentage of patients with CTD-PAH is lower in Poland than in other countries. This observation suggests lower recognition of CTD-PAH and thus lower availability of treatment which could improve quality and length of life in this group of patients.

\section{CHARACTERISTICS OF THE MOST COMMON CONNECTIVE TISSUE DISEASES}

The term CTD encompasses a large group of diseases characterized by the involvement of multiple systems and organs and assumed to be of autoimmune nature. The following diseases or subgroups of diseases belong to the CTD group: rheumatoid arthritis, systemic lupus erythematosus, systemic vasculitides, systemic sclerosis, inflammatory myopathies, Sjögren's syndrome, juvenile idiopathic arthritis, and mixed connective tissue disease. In some cases, overlap syndromes are diagnosed in which symptoms and lesions of two CTDs coexist. The onset of symptoms and lesions indicative of CTD but in a type and degree that does not allow the diagnosis of a specific CTD may be the basis for the diagnosis of undifferentiated CTD.

Diagnosis of CTD is difficult, primarily because of the varied clinical presentation and lack of pathognomonic indicators. One problem is overdiagnosis and, above all, misdiagnosis of these conditions based on autoantibodies alone which is, unfortunately, a common medical error. Classification criteria are helpful in the diagnosis of CTD. They are not diagnostic criteria and are therefore only used as an aid in the diagnostic process.

Rheumatoid arthritis (RA)-is a CTD characterized by multi-joint inflammation which primarily affects small joints, often occurs symmetrically, and leads to joint destruction, deformity, and synostosis, and thus results in disability. Arthritis is accompanied by changes in the tendon sheaths and synovial bursae, extra-articular changes (interstitial lung disease, pleural and pericardial effusions, and rheumatoid nodules in internal organs, e.g., in the lungs), and systemic symptoms (low-grade fever, fatigue, and lymphadenopathy). Serum from patients contains rheumatoid factor (an autoantibody directed against the $\mathrm{Fc}$ fragment of human immunoglobulin class $\mathrm{G}$ ), which usually belongs to the immunoglobulin class $M$ and less frequently to the immunoglobulin class $\mathrm{G}$ or $\mathrm{A}$, anti-citrullinated protein antibodies, and, of less diagnostic significance, antibodies against carbonylated proteins [4].

Systemic lupus erythematosus is a chronic autoimmune disease that can affect virtually all systems and organs, with a progressive course consisting of exacerbations and remissions. Numerous autoantibodies are present in the serum of patients, including antinuclear antibodies with different types of fluorescence (homogeneous, membrane, and patchy). Antibodies against native (double-stranded) DNA and anti-Sm antibodies have significant specificity. A decrease in the $C_{3}$ and $C_{4}$ complement components is also observed, which is helpful in assessing disease activity. The occurrence of anti-RNP antibodies is associated with the risk of developing myositis [5].

Systemic vasculitides are a large group of diseases with a common feature of inflammation in the vessel wall. CTDs include vasculitis with a suggested autoimmune cause, and may accompany other CTDs (e.g., SLE, RA). A distinction is made between the inflammation of large vessels (Takayasu's arteritis, giant cell arteritis), inflammation of medium arteries (polyarteritis nodosa, Kawasaki disease), small vessel antineutrophil cytoplasmic antibody-associated vasculitis (granulomatosis with polyangiitis, formerly known as Wegener's granulomatosis, microscopic polyangiitis, eosinophilic granulomatosis with polyangiitis or Churg- 
Strauss syndrome), small-vessel vasculitis associated with immune complexes (a disease associated with antibodies to the basement membrane of the glomeruli - Goodpasture's syndrome; vasculitis with cryoglobulinemia; IgA vasculitis - Henoch-Schönlein purpura; urticarial vasculitis with hypocomplementemia), vasculitis of different size of the vessels (Behçet's disease, Cogan's syndrome), and vasculitis limited to one organ (cutaneous small-vessel vasculitis, primary angiitis of the central nervous system).

Granulomatosis with polyangiitis, formerly known as Wegener's granulomatosis, is characterized by necrotizing granulomatous inflammation in the upper and lower respiratory tract, kidneys, skin, and heart, as well as other organs. It is a serious progressive disease. Patients are found to have anti-neutrophil cytoplasmic antibodies (ANCA) with cytoplasmic granular fluorescence (cANCA), which are directed against proteinase 3 and may have pathogenetic significance.

Perinuclear anti-neutrophil cytoplasmic antibodies (pANCA) are most commonly found in patients with microscopic polyangiitis (kidney, lung, skin, and peripheral nerve involvement). The pANCA antibodies are directed against myeloperoxidase.

Eosinophilic granulomatosis with polyangiitis, formerly known as Churg-Strauss syndrome, is a generalized necrotizing vasculitis with abundant tissue infiltrates composed of eosinophils, and eosinophilia is found in peripheral blood. Vasculitis accompanies asthma and nasal polyps. Eosinophilia, pANCA antibodies, asthma, lung infiltrates (found with imagining techniques), and peripheral polyneuropathy are important in the diagnosis [6].

Systemic sclerosis (which should not be referred to as scleroderma because the disease does not only affect the skin) is a severe disease characterized by vascular changes, autoantibodies, and progressive fibrosis of the skin and internal organs. SSc should be distinguished from localized scleroderma, which is a separate dermatologic disease. SSC has several forms. Diffuse SSc (symmetrical, rapidly progressive cutaneous lesions involving the face, proximal parts of limbs, and trunk developing together with involvement of internal organs) and limited SSc (not to be confused with localized $\mathrm{SSc}$ ) in which skin lesions which precede internal organ manifestations and involve the face and distal parts of limbs are most commonly found. Almost all patients show Raynaud's phenomenon, which may precede the onset of other symptoms. Patients have antinuclear antibodies against topoisomerase I ( $\mathrm{Scl}-70$ - more often in diffuse form), anti-centromere antibodies (ACA - more often in limited form), and other antibodies. $\mathrm{PH}$ is more common in the limited form of the disease [7].

Inflammatory myopathies are a group of diseases that include polymyositis, dermatomyositis, necrotizing autoimmune myositis, and inclusion body myositis. It is believed that the diseases are autoimmune in nature. They are characterized by muscle weakness and other changes, including frequent involvement of the lungs. Patients have multiple types of antibodies, and some patients do not have detectable autoantibodies. Histopathological examination of a muscle biopsy may be crucial for the diagnosis [8].

Antiphospholipid syndrome, known as Hughes syndrome, is a disease associated with autoantibodies to protein-phospholipid complexes causing venous thrombosis, arterial thrombosis, and pregnancy-related complications. Antiphospholipid syndrome can be primary or secondary, i.e., associated with another CTD - most commonly SLE. Thrombosis, pregnancy-related complications, anti-cardiolipin antibodies, anti-lipoprotein antibodies, and lupus anticoagulants are important in the diagnosis. Clinical manifestation of the antiphospholipid syndrome can be very variable and the course very severe [9].

Sjögren's syndrome (SS) is an autoimmune disease in which the glands of external secretion, such as the eye, mouth, and other parts of the gastrointestinal tract, become inflamed. SS may precede the development of lymphomas. The disease may be primary, or it may accompany other CTDs. SSA (Ro), SSB (La), Ro-52, as well as antinuclear antibodies and RF are found in the patients [10].

Mixed connective tissue disease, although includes symptoms typical of other CTDs, is not an overlap syndrome but a separate disease entity [11].

In summary, CTDs are systemic autoimmune diseases, which distinguishes them from organ-directed autoimmune diseases (e.g., Hashimoto's thyroiditis). Most patients have autoantibodies that are not themselves diagnostic. The organ lesions are highly variable and often involve the respiratory and cardiovascular systems, with vasculitis being common. All diseases also lead to increased cardiovascular mortality, in part due to accelerated atherosclerosis [12].

\section{Section summary}

- The term CTDs defines a large group of diseases that are autoimmune in nature and characterized by the involvement of multiple organs and systems.

- CTDs are characterized by cardiovascular and respiratory involvement.

- CTDs lead to increased cardiovascular mortality and accelerated atherosclerosis.

\section{DEFINITION, CLASSIFICATION, AND EPIDEMIOLOGY OF PULMONARY HYPERTENSION}

$\mathrm{PH}$ is diagnosed when the mean pulmonary artery pressure (mPAP) measured at rest during cardiac catheterization is $\geq 25 \mathrm{~mm} \mathrm{Hg}$ [13]; however, a recent expert opinion proposed that $\mathrm{PH}$ should be diagnosed when mPAP $>20 \mathrm{~mm}$ $\mathrm{Hg}$ [14]. Precapillary $\mathrm{PH}$, isolated postcapillary $\mathrm{PH}$, and combined postcapillary and precapillary $\mathrm{PH}$ are distinguished through consideration of the hemodynamic findings, including pulmonary artery wedge pressure (PAWP) and pulmonary vascular resistance (PVR) (precapillary $\mathrm{PH}$ : 
PAWP $\leq 15 \mathrm{~mm} \mathrm{Hg}$ and PVR $\geq 3$ Wood Units [WU]; isolated postcapillary PH: PAWP $>15 \mathrm{~mm} \mathrm{Hg}$ and PVR $<3 \mathrm{WU}$, and combined postcapillary and precapillary $\mathrm{PH}$ : $\mathrm{PAWP}>15 \mathrm{~mm}$ $\mathrm{Hg}$ and PVR $\geq 3 \mathrm{WU}$ ). Based on etiology, pathophysiology, clinical presentation, and treatment strategy, $\mathrm{PH}$ cases are classified into one of the five groups shown in Table 1 [14].

$\mathrm{PH}$ from different clinical groups is possible in patients with CTD. For example, in a group of patients with SSc of $\geq 3$ years of duration and a diffusing capacity for carbon monoxide (DLCO) $<60 \%$ of normal value, $\mathrm{PH}$ was found in $31 \%$ of patients, of whom $60 \%$ had PAH, $27 \%$ had $\mathrm{PH}$ due to lung disease, and $21 \%$ had $\mathrm{PH}$ due to left heart disease [15].

Early recognition of PAH in patients is particularly important because of the potential for targeted therapy. It is a clinical condition characterized by the presence of precapillary $\mathrm{PH}$ that is not the result of lung disease, CTEPH, or other intermittent causes of precapillary $\mathrm{PH}$ (clinical classification group 5). PAH includes a variety of forms with similar clinical presentation (Table 1, Group $1 \mathrm{PH}$ ) and similar pathomorphological changes in the pulmonary microcirculation [13].

In the group of patients with PAH (mPAP $\geq 25 \mathrm{~mm} \mathrm{Hg}$ ) in Poland $(n=970)$, idiopathic or inherited PAH (48\%), PAH associated with congenital heart disease (37\%), and PAH associated with CTDs (CTD-PAH; 14\%) were most commonly diagnosed [16-18]. Patients with CTD accounted for 30\% of all patients with PAH in the Scottish registry, $25 \%$ of all in the US registry, and 15\% of all in the French registry [19].

$\mathrm{SSC}$ is the most common systemic CTD in patients with $\mathrm{PAH}$. Among patients with CTD-PAH in Poland, the most common diagnoses are SSC (48\%), MCTD (17\%), RA (11\%), and SLE (10\%) [16]. The incidence of PAH in patients with SSc in registries from various countries was estimated between $2.9 \%$ and $19 \%[20,21]$. The risk of developing PAH in these patients increases with disease duration. In a 15-year follow-up, PAH was diagnosed in $17 \%$ of patients with the limited form of SSC and in 10\% with the diffuse form of SSC $[21,22]$. The incidence of PAH was not assessed in Polish SSC patients. However, taking the number of patients diagnosed with SSc-PAH and the number of patients with SSc (according to various sources from nearly 4000 to 10000) into account, it can be estimated that PAH is diagnosed in no more than $1.6 \%$ of patients with SSc $[23,24]$. This probably reflects inadequate screening for PAH in Polish patients with SSc.

The prognosis of SSc-PAH is poor and depends on the functional class at the time of diagnosis. In a French registry in which $72 \%$ of patients were diagnosed with World Health Organization (WHO) functional class III or IV, survival at 1,3 , and 5 years of follow-up was $87 \%, 55 \%$, and $35 \%$, respectively [25]. In contrast, in the PHAROS registry, in which the majority (59\%) of patients had a diagnosis of $\mathrm{PAH}$ with WHO functional class I or II, the survival rates were $95 \%, 75 \%$, and $63 \%$, respectively [26].
Table 1. Clinical classification of pulmonary hypertension

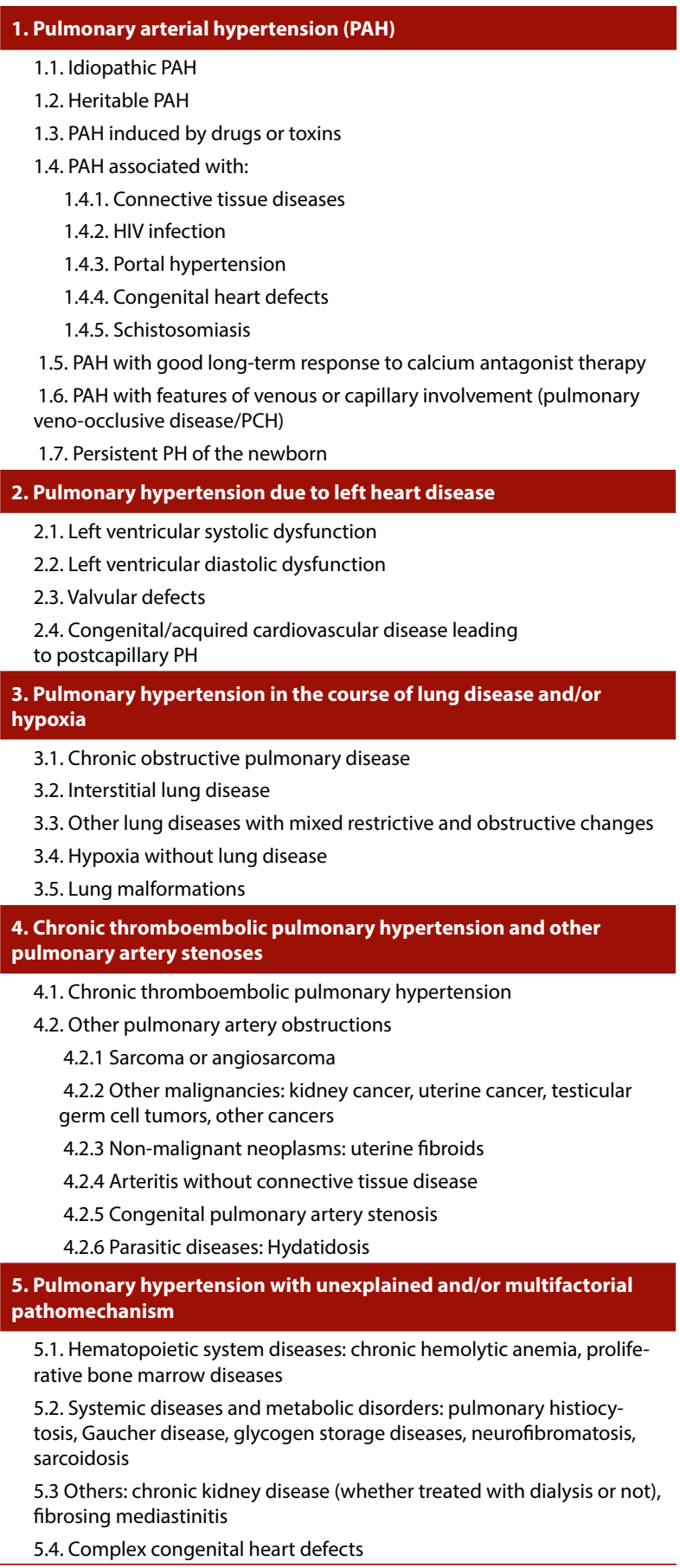

Abbreviations: HIV, human immunodeficiency virus; $\mathrm{PAH}$, pulmonary arterial hypertension; $\mathrm{PCH}$, pulmonary capillary hemangiomatosis.

\section{Section summary}

- CTD is the third most common cause of PAH in Poland. Patients with SSc are at the greatest risk of developing $\mathrm{PAH}$.

- The prevalence of PAH in patients with SSc in Poland is lower than in Western European countries; therefore, systematic screening of this group of patients is necessary.

- The prognosis of patients with PAH associated with SSC is poor but improves with early diagnosis. 
Table 2. Prevalence of pulmonary hypertension in patients with systemic connective tissue diseases (from various sources)

\begin{tabular}{|c|c|c|}
\hline Disorder & Prevalence & Comments \\
\hline Rheumatoid arthritis & $<1 \%$ & Common association with chronic respiratory symptoms \\
\hline $\begin{array}{l}\text { Systemic lupus } \\
\text { erythematosus }\end{array}$ & $1 \%-3 \%$ & $\begin{array}{l}\text { Unfavorable prognosis is associated with WHO Functional class III/IV, higher mean pulmona- } \\
\text { ry arterial pressure, lower } 6 \text { minutes walking distance, and higher N-terminal proBNP }\end{array}$ \\
\hline Systemic vasculitides & $\begin{array}{l}1 \%-3 \% \text {; higher rate in patients with } \\
\text { antineutrophil cytoplasmic antibody } \\
\text {-associated vasculitis (about } 10 \% \text { ) }\end{array}$ & $\begin{array}{l}\text { In most cases } \mathrm{PH} \text { is caused by pulmonary thromboembolism, } \mathrm{PAH} \text { is relatively rare; } \\
\text { renal and skin involvement is commonly associated with } \mathrm{PH}\end{array}$ \\
\hline Systemic sclerosis & $\begin{array}{c}\text { PAH } 8-15 \% \\
\text { Mixed forms of } \mathrm{PH} \text { are more common }\end{array}$ & See text \\
\hline $\begin{array}{l}\text { Inflammatory my- } \\
\text { opathy }\end{array}$ & $5 \%-50 \%$ & $\begin{array}{l}\text { High prevalence in patients with interstitial lung disease and anti-aminoacyl-transfer RNA } \\
\text { synthetases autoantibodies. Higher prevalence in Asian population }\end{array}$ \\
\hline $\begin{array}{l}\text { Antiphospholipid } \\
\text { syndrome }\end{array}$ & $5 \%-15 \%$ & $\begin{array}{l}\text { The majority of patients develop chronic thromboembolic pulmonary hypertension; some } \\
\text { suffer from PH after acute pulmonary thromboembolism. High titer of antiphospholipid } \\
\text { antibodies is considered as a risk factor }\end{array}$ \\
\hline Sjögren's syndrome & $5 \%-20 \%$ & $\begin{array}{l}\text { In most cases, } \mathrm{PH} \text { is related to pulmonary involvements in patients } \\
\text { with primary Sjögren's syndrome. PAH is relatively rare. Prevalence of PH is significantly } \\
\text { common in female Asian patients with non-specific intestinal pneumonia. } \\
\text { Early Raynaud's phenomenon is a risk factor for PH }\end{array}$ \\
\hline $\begin{array}{l}\text { Mixed connective } \\
\text { tissue disease }\end{array}$ & $2-8 \%$ & $\begin{array}{l}\text { Occurrence of significant symptoms and signs akin to systemic sclerosis are associated } \\
\text { with a higher prevalence of PH }\end{array}$ \\
\hline
\end{tabular}

Abbreviations: $\mathrm{PH}$, pulmonary hypertension; WHO, World Health Organization. Other — see Table 1

\section{THE ROLE OF THE RHEUMATOLOGIST IN THE DIAGNOSIS OF PULMONARY ARTERIAL HYPERTENSION}

$\mathrm{PH}$ can develop in the course of most CTDs but is by far the most common in SSc and SSc-related diseases such as MCTD and some forms of myositis [27]. The most common form is PAH, which affects approximately $8 \%-15 \%$ of SSc patients $[27,28]$. The multi-organ nature of CTDs also increases susceptibility to other forms of $\mathrm{PH}$. Thromboembolic PH may occur (e.g., with the antiphospholipid syndrome), as can $\mathrm{PH}$ resulting from pulmonary veno-occlusive disease seen in SSc. Mixed forms of PH are also possible, e.g., the coexistence of $\mathrm{PAH}$ with $\mathrm{PH}$ in patients with interstitial lung disease or heart disease [27]. Table 2 summarized the prevalence of $\mathrm{PH}$ in patients with various CTDs. It is worth noting that several studies provided different results due to various methodologies of $\mathrm{PH}$ detection, criteria of CTDs, and different populations of investigated patients.

$\mathrm{PH}$ is always associated with a worse prognosis, including a higher risk of death. The prognosis of patients with PAH in CTD depends on the underlying disease, with the highest risk of death found in patients with SSc [15, 27]. The analysis of the American REVEAL registry (the Registry to Evaluate Early and Long-term Pulmonary Arterial Hypertension Disease Management) showed that one-year survival in patients with idiopathic $\mathrm{PAH}$ was $93 \%$ compared to $86 \%$ in patients with $\mathrm{PAH}$ in the course of CTD, including $82 \%$ in SSC patients with $\mathrm{PAH}, 88 \%$ in MCTD patients with $\mathrm{PAH}, 94 \%$ in SLE patients with $\mathrm{PAH}$, and $96 \%$ in RA patients with PAH [29].

Due to its relatively frequent occurrence and progressive course, $\mathrm{PAH}$ is now the second most common cause of death in SSc patients, next to interstitial lung disease [30]. The prognosis of PAH depends on its clinical stage. Early diagnosis of PAH is therefore crucial to improve prognosis, especially since drugs are available that can slow disease progression.
Diagnosis of PAH in the early stages is not easy because of the low sensitivity and specificity of clinical signs. In the early stages of the disease, the patient may not feel any discomfort, especially considering the fact that the physical function of patients is often limited due to the musculoskeletal complaints that are very common in CTD. Secondly, the patient's adaptation to the chronically developing disease process means that symptoms are not felt until very advanced stages. Thirdly, decreased exercise tolerance in the absence of very discrete $\mathrm{PH}$ physical symptoms may be overlooked or misinterpreted as an expression of CTD or age, especially in patients over 50 years old. Therefore, early diagnosis of $\mathrm{PH}$ requires vigilance on the part of physicians caring for patients with CTD and regular evaluation of these patients for $\mathrm{PH}$.

In clinical practice, it may be helpful to know the profile of patients at higher risk of developing $\mathrm{PH}$. As mentioned above, PAH is particularly common in SSc and CTD patients with similar clinical presentations (MCTD, overlap syndromes with SSc). Risk factors for PAH in patients with SSc are listed in Table 3. It is worth noting that PAH develops relatively frequently in patients with skin lesions limited to the distal parts of the extremities, often only the fingers (socalled sclerodactyly or simply swollen fingers), which can easily be overlooked by both the patient and the medical

Table 3. Risk factors for pulmonary arterial hypertension in patients with systemic sclerosis

Risk factors for pulmonary arterial hypertension in patients with systemic sclerosis

A limited form of systemic sclerosis*

Presence of anti-centromere antibodies

Presence of telangiectasia

Longer duration of illness

Older age

Elevated uric acid levels

*The limited form of systemic sclerosis is characterized by the involvement of the skin only in the distal parts of the body (below the line of elbows and knees; the face is usually also involved) 


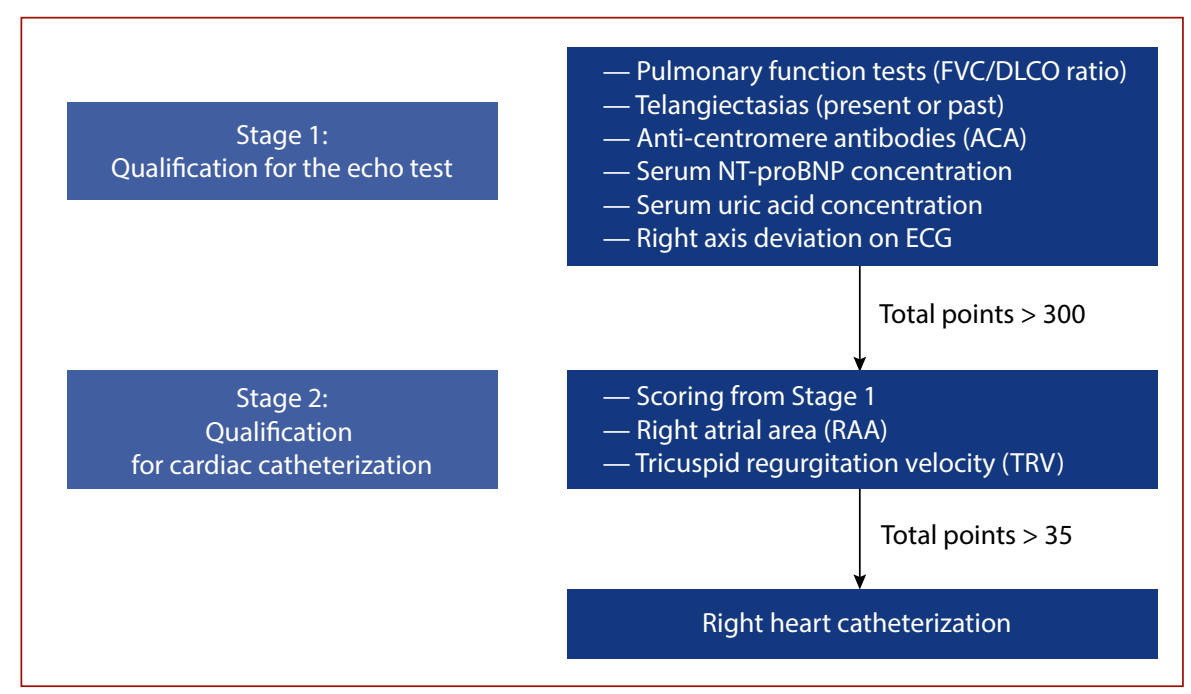

Figure 1. Evidence-based detection of pulmonary arterial hypertension in systemic sclerosis. Based on [15]

Abbreviations: DLCO, diffusing capacity for carbon monoxide; FVC, forced vital capacity

staff. Sometimes exertional dyspnea is the reason for seeking help and making the diagnosis of CTD. Unfortunately, at this stage, lung disease (PAH and/or interstitial lung disease) is usually already very advanced. Therefore, all patients with Raynaud's syndrome (present in almost all SSc patients from the onset of the disease), SSc-specific antibodies (especially ACA) and/or SSc-specific microangiopathy present, and even discrete skin lesions should be evaluated for $\mathrm{PH}$. Regarding telangiectasias, it is worth remembering that those typical of SSc have a regular shape (round or oval) and are usually observed on the face, hands, and/or neckline.

International guidelines recommend regular screening of patients with SSc and SSc-associated diseases for $\mathrm{PH}$ [21, 31-33]. Echocardiography plays a major role in screening. The importance of this test in the diagnosis of $\mathrm{PH}$ in patients with CTD is discussed in a separate section. Unfortunately, in practice, it is not always possible to evaluate all patients annually with echocardiography. The test can also produce false-negative results, especially in patients with early $\mathrm{PH}$ without tricuspid regurgitation, which prevents the estimation of right heart pressures.

The inclusion of other clinical, functional, and biochemical parameters in screening may improve the detection of PAH in patients with CTD [21, 28, 31-33]. The DETECT algorithm, based on the analysis of the aforementioned study, is designed to determine the risk of PAH in patients with SSc [15]. As shown in Figure 1, the DETECT algorithm includes two steps: the first is to assess the need for echo and the second is to qualify for right heart catheterization. In the first stage, the forced vital capacity/diffusion capacity of the lung for carbon monoxide ratio, the presence of telangiectasias (current or past), the presence of ACA antibodies, serum NT-proBNP and uric acid levels, and the right axis deviation on the ECG recording are evaluated. Individual parameters are assigned points based on the developed nomograms. A total score greater than 300 in- dicates the need for echocardiography. The second stage considers the scores from the first stage, the tricuspid regurgitation velocity, and the right atrium area. As in stage one, all parameters are prescribed scores based on nomograms. A second stage total score greater than 35 indicates the need for right heart catheterization.

The DETECT algorithm proved to be more sensitive compared with the echo study (evaluation according to European Society of Cardiology [ESC], and European Respiratory Society [ERS] guidelines): the sensitivity of the DETECT algorithm was $96 \%$ compared with $71 \%$ for the echo study. Similarly, the negative predictive value of the DETECT algorithm was higher (98\%) compared with the echo study (89\%). The DETECT calculator is available online on the website and as an app.

According to recent recommendations, patients with SSc and other CTDs with features of SSc (sclerodactyly, characteristic microangiopathy, and/or antibodies) and DLCO values $<80 \%$ of normal values should undergo annual screening for $\mathrm{PH}$ [32]. As illustrated in Figure 2, patients with suspected PH based on the DETECT algorithm (DETECT score $>35$ points) or echocardiography with forced vital capacity (FVC) / DLCO >1.6 and/or NT-proBNP levels exceeding the upper limit of normal 2 times (after excluding other causes) should be referred to centers specializing in diagnosing $\mathrm{PH}$ for right heart catheterization.

Clinical studies suggest that the use of $\mathrm{PH}$ screening programs in practice enables earlier diagnosis and treatment of $\mathrm{PAH}$, which in turn improves prognosis in this group of patients [21, 26, 32-33].

\section{Section summary}

- Risk factors for PAH in patients with SSc include limited SSc, presence of ACA antibodies, presence of telangiectasias, longer duration of disease, older age, and elevated uric acid levels. 


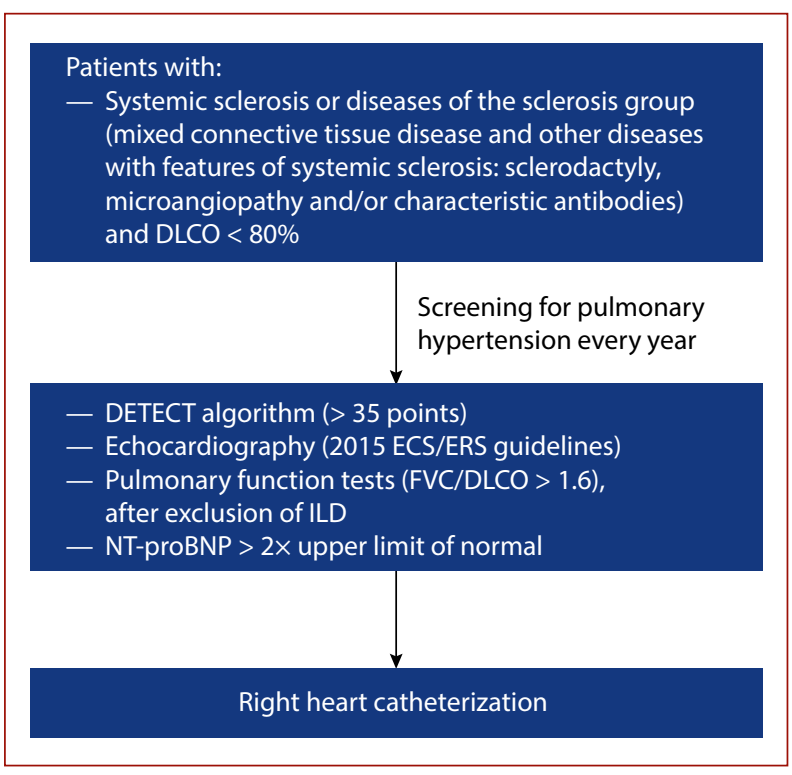

Figure 2. Algorithm to detect pulmonary hypertension in patients with SSc/scleroderma spectrum disorders. Based on [32]

Abbreviations: ILD, interstitial lung disease. Other — see Figure 1

- Screening for PH should be based on a comprehensive assessment that includes risk factors, clinical presentation, and additional test results, including pulmonary function tests (FVC, DLCO), NT-proBNP/BNP, and uric acid levels.

- The DETECT algorithm facilitates the selection of patients who require echocardiography and right heart catheterization and increases the sensitivity of diagnosing PAH in SSc patients.

- Patients with PH in the course of CTD should be cared for by a multi-specialist team consisting of a rheumatologist and a cardiologist.

\section{PULMONARY ARTERIAL HYPERTENSION IN CONNECTIVE TISSUE DISEASES: THE CARDIOLOGIST'S ROLE IN DIAGNOSIS}

The primary goals of cardiological diagnosis in a patient with suspected $\mathrm{PAH}$ are to determine the indications for invasive diagnosis (right heart catheterization), to establish the diagnosis of $\mathrm{PH}$ and its type, and to determine the possibility of including PAH-targeted therapy, which depends on confirmation of PAH or CTEPH.

An established diagnosis of SSc or SSc-related diseases is a strong risk factor for the occurrence of PAH with an extremely unfavorable prognosis and increases the risk of deep vein thrombosis severalfold, which can lead to CTEPH [34]. The coexistence of interstitial lung disease in the setting of CTD (including capillary and small pulmonary vein pathology) is a problem typical for SSc, which may exclude patients from PAH-targeted therapies. Forced expiratory volume in one second $\left(\mathrm{FEV}_{1}\right)<70 \%$ (obturation) and FVC $<70 \%$ (restriction) are taken as criteria supporting a predominant role of pulmonary etiology.
The diagnosis of PAH in a patient with CTD may follow two diagnostic pathways. The first pathway applies to the evaluation of a patient with symptoms suggestive of PAH (which are difficult to distinguish from symptoms of pulmonary complications of SSc). The second pathway applies to the evaluation of a patient without specific symptoms undergoing annual screening for CTD from the SSc spectrum.

The evaluation of a symptomatic patient with CTD does not differ from the general criteria used in PAH. Typical symptoms warrant urgent echocardiography with the assessment of the likelihood of $\mathrm{PH}$ and its clinical implications. An asymptomatic patient should be referred to a cardiologist for echocardiography as part of a screening program either once per year (if an echocardiographic screening strategy is chosen and echocardiography is readily available in a center specializing in the assessment of right-sided cardiac circulation), or in the event of a positive screening test if another screening strategy is used (e.g., FVC/DLCO ratio $>1.6$ and/or NT-proBNP concentration $>2$ times normal; DETECT algorithm with the index after stage I more than 300 points).

Echocardiography is the primary noninvasive method for determining the risk of $\mathrm{PH}$. Its evaluation requires measurement of maximum tricuspid regurgitation velocity and phenotypic features of cardiac imaging in $\mathrm{PH}$. The examination should be performed by a center specializing in the assessment of the pulmonary circulation in optimal technical quality, using the projections optimized for assessment of the right-sided cardiac cavities [35]. The evaluation principles are shown in Table 4.

In a symptomatic patient with CTD, a finding of intermediate or high probability is a relative (recommendation class $\mathrm{Ila} / \mathrm{B}$ ) or an absolute (I/C) indication, respectively, for a full $\mathrm{PH}$ evaluation in a specialized center with consideration of right heart catheterization. In an asymptomatic patient with SSc, a finding of intermediate probability is a relative indication for right heart catheterization (recommendation class $\mathrm{Ila} / \mathrm{B})$, whereas a high probability with any CTD is an absolute $(\mathrm{I} / \mathrm{C})$ indication for a full $\mathrm{PH}$ evaluation in a specialized center including right heart catheterization.

If echocardiography is used as the second stage of the DETECT algorithm, echocardiographic assessment of the maximal (end-systolic) right atrial area assessed in the four-chamber view and the velocity of the maximal tricuspid regurgitant return wave is crucial. If the threshold of 35 points is exceeded in the second stage of the algorithm, right heart catheterization at an expert $\mathrm{PH}$ center is indicated.

In most patients, pulmonary ventilation-perfusion scintigraphy, computed tomography pulmonary angiography, or conventional pulmonary cineangiography during right heart catheterization is necessary to rule out a pulmonary artery thromboembolism component regardless of the patient's history. High resolution computed tomography of the lungs aids in the differential diagnosis of uncom- 
Table 4. Algorithm for assessing the likelihood of pulmonary hypertension on transthoracic echocardiography according to [31]

\begin{tabular}{l|c|c}
\multicolumn{1}{c|}{$\begin{array}{c}\text { Maximum tricuspid regurgitation } \\
\text { wave velocity, } \mathbf{m} / \mathbf{s}\end{array}$} & $\begin{array}{c}\text { Presence of other echocardiographic } \\
\text { features of pulmonary hypertension* }\end{array}$ & $\begin{array}{c}\text { Echocardiographic probability } \\
\text { of pulmonary hypertension }\end{array}$ \\
$\leq 2.8$ or not measurable & No & Low \\
$\leq 2.8$ or not measurable & Yes & Intermediate \\
$2.9-3.4$ & No & High \\
$2.9-3.4$ & Yes & \\
$>3.4$ & Not required & \\
\hline
\end{tabular}

*At least two features from three categories suggesting: right ventricular enlargement, increased pulmonary artery pressure or increased pulmonary vascular resistance, features indicative of high right atrial pressure

mon pulmonary capillary hemoangiomatosis/pulmonary venoocclusive disease, which require different therapeutic approaches. Right heart catheterization is the definitive diagnostic method to establish the hemodynamic indices necessary to establish the diagnosis of PAH (see the section on classification and criteria) and the decision to initiate targeted therapies. These indices include mPAP, PVR (using reversibility tests after administration of nitric oxide or prostacyclin analogs), and possibly the trans-pulmonary gradient. In borderline cases with difficult differentiation of precapillary and postcapillary components, additional measurement of PCWP during exercise or after fluid loading may be performed. Existing treatment recommendations have been established in studies of patients who meet the traditional definition of $P H$, i.e., $\mathrm{mPAP} \geq 25 \mathrm{~mm} \mathrm{Hg}$.

\section{Section summary}

- Asymptomatic patients with CTD on the SSc spectrum should undergo annual screening for $\mathrm{PH}$, and in Polish conditions, echocardiography may be the preferred, most universal method (recommended regardless of the DLCO result). In other types of CTD, echocardiography is performed when $\mathrm{PH}$ is clinically suspected.

- The decision on whether indications warrant right heart catheterization to establish a conclusive diagnosis is made by the cardiologist, and the examination should be performed in expert PH centers. The DETECT algorithm is useful in patient selection for right heart catheterization.

- The final determination of the type of PH and the appropriateness of inclusion in a treatment program for patients with CTD should be undertaken in expert PH centers.

\section{TREATMENT OF PULMONARY ARTERIAL HYPERTENSION}

Patients with CTD who are diagnosed with PAH should be treated the same as all other patients with category I PH, according to current guidelines. This is because in most of the large, randomized trials conducted to register drugs for PAH, approximately $30 \%$ of patients were CTD patients [31, 36]. The only difference is that high-dose calcium antagonists are not recommended in patients with CTD-PAH, as a positive response has been reported in less than $1 \%$ of patients [37]. Anticoagulants are also not used due to the unfavorable risk/benefit ratio of bleeding [38].

Treatment of $\mathrm{PAH}$ is always done at a referral center. There are currently $24 \mathrm{PAH}$ treatment referral centers for adults and nine pediatric centers in Poland (PAH treatment centers in Poland: www.skp.ptkardio.pl/osrodki_dorosli, www. skp.ptkardio.pl/osrodki-dzieci).

\section{General recommendations}

- Encourage patients to engage in symptom-limited physical activity and supervised rehabilitation.

- Influenza and pneumococcal vaccinations.

- Iron suplementation should be considered in patients with iron deficiency: serum ferritin $<100 \mu \mathrm{g} / \mathrm{l}$, or ferritin between 100-299 $\mu \mathrm{g} / \mathrm{l}$ and transferrin saturation $<20 \%$.

- Diuretics in patients with fluid retention.

- Oxygen therapy: when arterial blood oxygen partial pressure is $<60 \mathrm{~mm} \mathrm{Hg}$ or when arterial blood oxygen saturation is $<91 \%$, oxygen is recommended for at least 15 hours per day.

\section{Targeted pharmacotherapy \\ (specific to pulmonary arterioles)}

In the treatment of $\mathrm{PAH}$, three groups of drugs are used:

- Drugs that affect the endothelin pathway: endothelin receptor antagonists, which include ambrisentan, bosentan, and macitentan

- Drugs that affect the nitric oxide pathway: phosphodiesterase-5 inhibitors, which include sildenafil, tadalafil, vardenafil, and guanylyl cyclase stimulators, which include riociguat

- Drugs that affect the prostacyclin pathway: prostacyclins, which include beraprost, epoprostenol, iloprost, treprostinil, and IP prostacyclin receptor agonists, which include selexipag

Within the National Health Fund drug program for the treatment of PAH in Poland, bosentan, macitentan, sildenafil, riociguat, epoprostenol (iv), iloprost (inhaled), treprostinil (sc), and selexipag can be prescribed. All these drugs have vasodilatory effects and lower pulmonary artery pressure; however, they also have antiproliferative effects that reduce the proliferation of endothelial cells and pulmonary arterial smooth muscle. Parenteral prostacyclins have the strongest effect; in addition, they are the most potent endogenous inhibitors of platelet aggregation [31]. 
Table 5. Risk assessment in pulmonary arterial hypertension

\begin{tabular}{|c|c|c|c|}
\hline $\begin{array}{l}\text { Prognostic value (estimated } \\
\text { mortality within a year) }\end{array}$ & $\begin{array}{l}\text { Low risk } \\
<5 \%\end{array}$ & $\begin{array}{l}\text { Intermediate risk } \\
5-10 \%\end{array}$ & $\begin{array}{l}\text { High risk } \\
>10 \%\end{array}$ \\
\hline $\begin{array}{l}\text { Clinical manifestation of right } \\
\text { ventricular failure }\end{array}$ & No & No & Yes \\
\hline Rate of progression of symptoms & Absent & Slow & Fast \\
\hline Syncope & Absent & Sporadic & Frequent \\
\hline WHO functional class & I, II & III & IV \\
\hline Six-minute walk test & $>440 \mathrm{~m}$ & $165-440 \mathrm{~m}$ & $<165 \mathrm{~m}$ \\
\hline Ergospirometry & $\begin{array}{c}\mathrm{VO}_{2} \max >15 \mathrm{ml} / \mathrm{min} / \mathrm{kg} \\
(>65 \% \text { pred.) } \\
\text { VE } / \mathrm{VCO}_{2} \text { slope }<36\end{array}$ & $\begin{array}{c}\mathrm{VO}_{2} \max 11-15 \mathrm{ml} / \mathrm{min} / \mathrm{kg} \\
(35 \%-65 \% \mathrm{pred} .) \\
\text { VE/ } / \mathrm{VCO}_{2} \text { slope } 36-44.9\end{array}$ & $\begin{array}{c}\mathrm{VO}_{2} \max <11 \mathrm{ml} / \mathrm{min} / \mathrm{kg} \\
(<35 \% \text { pred. }) \\
\text { VE } / \mathrm{VCO}_{2} \text { slope } \geq 45\end{array}$ \\
\hline NT-proBNP serum concentration & $\begin{array}{c}\text { BNP }<50 \mathrm{ng} / \mathrm{l} \\
\text { NT-proBNP }<300 \mathrm{ng} / \mathrm{l}\end{array}$ & $\begin{array}{c}\text { BNP 50-300 ng/l } \\
\text { NT-proBNP 300-1400 ng/l }\end{array}$ & $\begin{array}{c}\text { BNP }>300 \mathrm{ng} / \mathrm{l} \\
\text { NT-proBNP }>1400 \mathrm{ng} / \mathrm{l}\end{array}$ \\
\hline $\begin{array}{l}\text { Imaging studies (echocardiography, } \\
\text { CMR) }\end{array}$ & $\begin{array}{c}\text { RAA }<18 \mathrm{~cm}^{2} \\
\text { no pericardial effusion }\end{array}$ & $\begin{array}{c}\text { RAA } 18-26 \mathrm{~cm}^{2} \\
\text { no or minimal pericardial effusion }\end{array}$ & $\begin{array}{c}\text { RAA }>26 \mathrm{~cm}^{2} \\
\text { pericardial effusion }\end{array}$ \\
\hline Hemodynamics & $\begin{array}{c}\mathrm{RAP}<8 \mathrm{~mm} \mathrm{Hg} \\
\mathrm{Cl} \geq 2.5 \mathrm{I} / \mathrm{min} / \mathrm{m}^{2} \\
\mathrm{SvO}_{2}>65 \%\end{array}$ & $\begin{array}{c}\mathrm{RAP} 8-14 \mathrm{~mm} \mathrm{Hg} \\
\mathrm{Cl} 2.0-2.4 \mathrm{I} / \mathrm{min} / \mathrm{m}^{2} \\
\mathrm{SvO}_{2} 60-65 \%\end{array}$ & $\begin{array}{c}\mathrm{RAP}>14 \mathrm{~mm} \mathrm{Hg} \\
\mathrm{Cl}<2.0 \mathrm{I} / \mathrm{min} / \mathrm{m}^{2} \\
\mathrm{SvO}_{2}<60 \%\end{array}$ \\
\hline
\end{tabular}

Abbreviations: BNP, B-type natriuretic peptide; $\mathrm{Cl}$, cardiac index; $\mathrm{CMR}$, cardiac magnetic resonance; NT, N-terminal; RAA, right atrial area; RAP, right atrial pressure; SVO ${ }_{2}$, venous oxygen saturation; $\mathrm{VE}$, minute ventilation; $\mathrm{VCO}_{2}$, carbon dioxide production; $\mathrm{VO}_{2}$, oxygen consumption; WHO, World Health Organization

The choice of initial therapy, as well as the timing of escalation of therapy in long-term follow-up, is based on an assessment of the risk of death within one year. Several risk stratification tools exist, including the REVEAL 2 scale [39], risk assessment based on the Swedish [40], French [41], COMPERA [42] registry, and ESC risk tables [31]. In Poland, the ESC risk stratification table is most commonly used (Table 5). The risk of death is assessed at baseline and at 4- to 6-month intervals thereafter, and considers a dataset derived from clinical assessment, six-minute walking test, ergospirometry, biochemical markers, echocardiography, and right heart catheterization. Although CTD-PAH is a more aggressive disease than idiopathic $\mathrm{PAH}$, this method of risk stratification has also been validated in this group of patients [43].

The earlier therapy is started, the better the results of $\mathrm{PAH}$ treatment. This applies to all patients with $\mathrm{PAH}$, including patients with CTD-PAH. In the French Registry, 3-year survival in patients with SSc was $80 \%$ when treatment started in NYHA class II, $72 \%$ in class III, and $30 \%$ in class IV [43]. There is also evidence that, in patients with CTD-PAH, survival is better when treatment is initiated as a result of screening than when diagnosis and treatment occur due to the severity of clinical symptoms [44].

According to the ESC and World Hypertension Forum recommendations, at low or intermediate risk of death, therapy should be initiated with two oral drugs from two different groups (endothelin receptor antagonist + phosphodiesterase-5 inhibitor) $[31,45]$. The National Health Fund drug program does not reimburse this course of action: the therapy has to start with one drug, but if it proves ineffective, another drug can be added. Expert groups of both societies contributing to this statement suggest eliminating this gap in the therapeutic program, as it does not comply with current ESC/ERS guidelines, while no longer being justified by financial reasons, as oral generic ET-1 receptor antagonists and PDE5i are currently availa- ble at a low cost. When the patient is initially at high risk, combination therapy, including prostacyclin, is applied.

The essence of managing a patient with $\mathrm{PAH}$ is to maintain assessed parameters within a low-risk-of-death profile, which is synonymous with a good prognosis. If some of these parameters fall into the intermediate or high-risk profile, it means that the patient is inadequately treated and the therapy needs to be intensified by the addition of another drug, change to a more potent one, or increase of the dose [46].

If triple-drug therapy is ineffective, patients should be referred for lung transplantation. Lung transplantation is not contraindicated in patients with CTD-PAH [47], although indications and contraindications must include evaluation of other organs that may be involved, particularly the gastrointestinal tract (reflux disease and intestinal disease), heart, kidney, and skin [47].

Despite targeted pharmacotherapy, the prognosis of patients with CTD, especially those with SSc and related diseases, is worse than that of patients with idiopathic PAH [48, 49]. A 2021 meta-analysis of 12 randomized trials and 19 registries with at least 30-patient subgroups with CTD-PAH from 2000 to 2019 showed a slightly lower mortality rate in patients with CTD, albeit still higher than in other groups of patients with $\mathrm{PAH}$. The 3-year survival was lower in patients with CTD-PAH vs all patients: $62 \%$ vs $72 \%$, respectively. The 3-year survival of patients with CTD-PAH after 2010 was better than before 2010 at $73 \%$ vs $65 \%$, respectively [50].

In a randomized trial involving 111 patients with SSc, 3-month treatment with intravenous epoprostenol infusion improved physical performance, hemodynamic parameters, and functional class [51]. Subgroup analyses of patients with CTD-PAH or SSc from randomized trials in which sildenafil, tadalafil, bosentan, ambrisentan, macitentan, subcutaneous treprostinil, riociguat, and selexipag were administered showed a beneficial effect of these drugs, 
although the improvement was not always statistically significant. Some of these studies showed that the treatment effect was smaller in patients with CTD-PAH than in patients with idiopathic PAH [52]. This could be because CTDs, which are systemic diseases, cause damage to multiple organs [27]. The small size of the CTD-PAH subgroups may also have had some influence on these results, hampering the achievement of statistically significant results. A common endpoint in these studies was the six-minute walking test, which may show worse results in patients with CTD because of the muscular or joint problems or fatigue associated with the underlying disease [27]. In contrast, since 2013, when the SERAPHIN, GRIPHON, and AMBITION trials were released, an analysis of subgroups of patients with CTD-PAH showed a significant reduction in the composite endpoint. In these studies, the endpoint included morbidity and mortality, and the time from study drug inclusion to the first incident (death, worsening, hospitalization for prostacyclin inclusion, lung transplantation, or septostomy) was assessed. In addition, in the SERAPHIN and GRIPHON trials, $64 \%$ and $80 \%$, respectively, were already receiving PAH-targeted therapy at baseline, so the addition of an investigational drug was often a combination therapy [53-56]. The AMBITION study additionally showed that, as in the overall group, in patients with CTD and in patients with SSc, initial treatment with tadalafil and bosentan was more beneficial than initial monotherapy [53]. The aforementioned 2021 meta-analysis, based on five randomized trials evaluating time to incident mortality/morbidity, showed the same $36 \%$ reduction in the risk of incident mortality/morbidity in treated vs placebo in the whole group as well as the CTD-PAH subgroup [46].

\section{Section summary}

- PAH in patients with CTD and especially in those with SSc has a high mortality rate.

- Prognosis can be improved by the earliest possible inclusion of targeted therapy, preferably based on screening.

- This treatment should be aggressive and include initial combination therapy.

- Targeted therapy given to patients with CTD-PAH improves the quality of life, physical function, and hemodynamics and reduces mortality/morbidity.

\section{DOES DIAGNOSIS OF PULMONARY ARTERIAL HYPERTENSION CHANGE THE MANAGEMENT OF A PATIENT WITH CONNECTIVE TISSUE DISEASE?}

The causes and mechanisms of CTD development are unknown, so treatment is limited to immunosuppressive drugs and symptomatic treatment of organ lesions. The essence of autoimmunization is the generation of immunity against one's own antigens. In the absence of the ability to correct impaired immune tolerance, treatment comes down to reducing the overall immune response. The drugs used combine immunosuppressive, anti-inflammatory, and antiproliferative effects, and delineating these actions is difficult. If a patient with CTD has PAH, the following issues regarding the interrelationship of CTD and PAH treatment should be considered:

- Does a decrease in the overall activity of the disease process in CTD reduce the occurrence and severity of PAH?

- Can drugs used in patients with CTD (e.g., symptomatic - affecting organ changes) exacerbate (or even trigger) the onset of PAH in this group of patients?

- Can drugs used in patients with CTD interact with the treatment of $\mathrm{PAH}$, and thus require modification of their simultaneous co-administration?

The therapeutic problems presented have no clear answer.

The incidence of PAH in CTD patients has been presented in earlier sections of this paper. There is a prevailing belief that the development of PAH is an expression of the severity of the disease, but there is no clear association with other indicators of disease process activity. Moreover, the clinical presentation of CTD is highly variable. Despite the lack of studies, however, it is plausible that the development of PAH shares a common pathogenesis with other organ lesions, and therefore, early and prolonged reduction in disease activity is beneficial to pulmonary circulation. However, detection of PAH usually occurs so late that reduction of disease activity alone is not sufficient to control PAH. A case of resolution of $\mathrm{PAH}$ and interstitial lung disease in an SLE patient after treatment with mycophenolate mofetil was described [57]. This is consistent with animal model studies in which the active metabolite of mycophenolate mofetil has been shown to inhibit pulmonary artery wall remodeling in rats. Similarly, intensive treatment of SLE with cyclophosphamide and corticosteroids may be associated with a reduction in PAH [58]. On the other hand, it has been reported that $\mathrm{PH}$ can be associated with an elevated level of mineralocorticoids and medication against mineralocorticoid activity is beneficial. Administration of glucocorticoids can exert some mineralocorticoid activity and such drug action should be considered. In most cases, anti-inflammatory and immunosuppressive action of glucocorticoids predominates their mineralocorticoid activity.

Administration of non-steroidal antirheumatic drugs is associated with inhibition of prostaglandin synthesis. It may an be additional unfavorable factor in patients with $\mathrm{PH}$, thus should be considered in a long-term therapeutic strategy.

There is no reliable evidence indicating lung injury and the occurrence of PAH in patients treated with immunosuppressive drugs. The few case reports refer to infectious complications that damage the lungs and may promote secondary development of PAH, rather than a direct effect of immunosuppressants causing PAH. Single case reports suggest that the disease-modifying drug leflunomide may induce PAH. Leflunomide is metabolized to teriflunomide, which inhibits de novo pyrimidine nucleotide 
synthesis. Moreover, the drug inhibits the activity of cyclooxygenase-2 and thus the production of prostaglandin $E_{2}$. This mechanism may be linked to the development of $\mathrm{PAH}$ [59]. Leflunomide has also been linked to the sporadic development of interstitial lung disease in RA patients [60].

Another disease-modifying drug, methotrexate, has antiproliferative effects at high doses and anti-inflammatory effects at lower concentrations through its effects on adenosine metabolism. The use of methotrexate has been linked to pulmonary fibrosis, but most contemporary studies show the opposite effect - inhibition of the inflammatory process reduces the development of pulmonary fibrosis [61]. No study has confirmed the impact of methotrexate on the development of PAH. Methotrexate is also used in proliferative hematopoietic diseases, and the beneficial effects of methotrexate on $\mathrm{PH}$ have been described in patients with T-lymphocytic leukemia [62]. Other drugs known to cause PAH are not regularly administered (and should not be administered) in patients with CTD.

Single case reports and uncontrolled clinical observations suggest that immunosuppressive drugs may be combined with drugs used to treat $\mathrm{PAH}$ - they seem to work synergistically. Adverse effects of bosentan in SSc patients have been described, including an increase in arthritis as well as an increase in methotrexate hepatotoxicity [63]. This is explained by the inhibitory effect of bosentan on endogenous glucocorticoid secretion. However, it is important to remember that the inflammatory process in SSc patients is revealed only in the early stages of the disease or in overlap syndromes between SSc and other CTDs.

\section{Section summary}

- In patients with CTD complicated by PAH, the underlying disease and PAH should be treated without modifying therapeutic strategy.

- Increasing the number of drugs used raises the risk of adverse interactions and requires more intensive therapeutic surveillance.

- The occurrence of PAH reduces the patient's exercise tolerance, which may require lifestyle changes, avoidance of respiratory infections, and changes in the rehabilitation used.

\section{SUMMARY}

Various organs and systems, including the cardiovascular and respiratory systems, may be involved in the course of CTD. One of the complications of CTD that affects the prognosis most heavily is $\mathrm{PH}$. The etiology of $\mathrm{PH}$ in patients with CTD is heterogeneous and includes $\mathrm{PAH}, \mathrm{PH}$ secondary to interstitial lung disease, postcapillary $\mathrm{PH}$ secondary to left heart disease, and CTEPH. In addition, several PH mechanisms may coexist in a patient, which significantly complicates diagnosis and treatment. Among CTD patients, $\mathrm{PAH}$ occurs most frequently in those with SSc, in whom it affects approximately $8 \%-12 \%$ of patients. $\mathrm{PH}$ should be suspected on the basis of clinical symptoms by the rheumatologist or cardiologist caring for the patient. The symptomatic patient should be referred to a cardiology center for diagnosis of $\mathrm{PH}$. In asymptomatic patients with SSc, echocardiography should be considered every year, or in the event of a positive screening test if another screening strategy is used (FVC/DLCO $>1.6$ and/or NT-proBNP levels $>2$ times normal or DETECT algorithm with a poststage I score of more than 300 points). Clinical suspicion of $\mathrm{PH}$ always requires confirmation with right heart catheterization, which also helps to determine the mechanism of $\mathrm{PH}$. Patients with confirmed PAH should be referred to a cardiology referral center for targeted therapy. The care for patients with CTD requires collaboration between the rheumatologist treating the underlying disease and the cardiologist diagnosing and treating $\mathrm{PH}$.

\section{Article information}

Conflict of interest: OK-B received fees and/or congress support grants from Bayer, Boehringer Ingelheim, CSL Behring, Gilead, Inventiva, Janssen-Cilag, Medac, MSD, Novartis, Pfizer, Roche, Sandoz. TM-K received fees and/or congress supports from Bayer, Janssen-Cilag, MSD, AOP Orphan.

Open access: This article is available in open access under Creative Common Attribution-Non-Commercial-No Derivatives 4.0 International (CC BY-NC-ND 4.0) license, allowing to download articles and share them with others as long as they credit the authors and the publisher, but without permission to change them in any way or use them commercially. For commercial use, please contact the journal office at kardiologiapolska@ptkardio.pl.

How to cite: Mularek-Kubzdela T, Ciurzyński M, Kowal-Bielecka O, et al. An expert opinion of the Polish Cardiac Society Working Group on Pulmonary Circulation and the Polish Society for Rheumatology on the diagnosis and treatment of pulmonary hypertension in patients with connective tissue disease. Kardiol Pol. 2021; 79(7-8): 917-929, doi: 10.33963/KP.a2021.0055.

\section{REFERENCES}

1. Mani $\mathrm{P}$, Gonzalez D, Chatterjee $\mathrm{S}$, et al. Cardiovascular complications of systemic sclerosis: what to look for. Cleve Clin J Med. 2019; 86(10): 685-695, doi: 10.3949/ccjm.86a.18109, indexed in Pubmed: 31597076.

2. Attanasio U, Cuomo A, Pirozzi F, et al. Pulmonary hypertension phenotypes in systemic sclerosis: the right diagnosis for the right treatment. Int J Mol Sci. 2020; 21(12): 4430, doi: 10.3390/ijms21124430, indexed in Pubmed: 32580360 .

3. Aithala R, Alex AG, Danda D. Pulmonary hypertension in connective tissue diseases: an update. Int J Rheum Dis. 2017; 20(1): 5-24, doi: 10.1111/1756185X.13001, indexed in Pubmed: 28205373.

4. Kucharz EJ. Reumatoidalne zapalenie stawów. In: Puszczewicz MJ. ed. Wielka Interna. Reumatologia. Medical Tribune, Warszawa 2016: 79-95.

5. Majdan M. Toczeń rumieniowaty układowy. Termedia, Poznań 2015.

6. Kucharz EJ. Zapalenia naczyń. In: Zimmermann-Górska I. ed. Terapia w chorobach reumatycznych. PZWL Wydawnictwo Lekarskie, Warszawa 2018: 204-250.

7. Hachulla E, Czirják L. EULAR Textbook on systemic sclerosis. BMJ Group, London 2013.

8. KucharzEJ. Idiopatyczne miopatie zapalne. In: Puszczewicz MJ. ed. Wielka Interna. Reumatologia. Medical Tribune, Warszawa 2016: 158-168.

9. Zawilska K, Zimmermann-Górska I. Zespól antyfosfolipidowy. In: Zimmermann-Górska I. ed. Terapia w chorobach reumatycznych. PZWL Wydawnictwo Lekarskie, Warszawa 2018: 270-287.

10. Kucharz EJ. Zespół Sjögrena. In: Olesińska MJ. ed. Reumatologia w gabinecie lekarza Podstawowej Opieki Zdrowotnej. PZWL Wydawnictwo Lekarskie, Warszawa 2019: 359-367. 
11. Olesińska M, Felis-Giemza A. Mieszana choroba tkanki łącznej. In: Zimmermann-Górska I, Felis-Giemza A. ed. Terapia w chorobach reumatycznych. PZWL Wydawnictwo Lekarskie, Warszawa 2018: 171-189.

12. Kucharz EJ. Chronic inflammation-enhanced atherosclerosis: can we consider it as a new clinical syndrome? Med Hypotheses. 2012; 78(3): 396-397, doi: 10.1016/j.mehy.2011.11.020, indexed in Pubmed: 22182962.

13. Perez Vd. Faculty Opinions recommendation of 2015 ESC/ERS guidelines for the diagnosis and treatment of pulmonary hypertension: the joint task force for the diagnosis and treatment of pulmonary hypertension of the European Society of Cardiology (ESC) and the European Respiratory Society (ERS): endorsed by: Association for European Paediatric and Congenital Cardiology (AEPC), International Society for Heart and Lung Transplantation (ISHLT). Eur Heart Jre. 2016; 37(1): 67-119, doi: 10.1093/eurheartj/ehv317, indexed in Pubmed: 26320113.

14. Simonneau G, Montani D, Celermajer D, et al. Haemodynamic definitions and updated clinical classification of pulmonary hypertension. Eur Respir J. 2019; 53(1): 1801913, doi: 10.1183/13993003.01913-2018.

15. Coghlan JG, Denton CP, Grünig E, et al. DETECT study group. Evidence-based detection of pulmonary arterial hypertension in systemic sclerosis: the DETECT study. Ann Rheum Dis. 2014; 73(7): 1340-1349, doi: 10.1136/annrheumdis-2013-203301, indexed in Pubmed: 23687283.

16. Kopeć $G$, Kurzyna M, Mroczek E, et al. Characterization of patients with pulmonary arterial hypertension: data from the Polish Registry of Pulmonary Hypertension (BNP-PL). J Clin Med. 2020; 9(1): 173, doi: 10.3390/jcm9010173, indexed in Pubmed: 31936377.

17. Kwiatkowska J, Zuk M, Migdal A, et al. Children and adolescents with pulmonary arterial hypertension: baseline and follow-up data from the Polish Registry of Pulmonary Hypertension (BNP-PL). J Clin Med. 2020; 9(6): 1717, doi: 10.3390/jcm9061717, indexed in Pubmed: 32503164.

18. KopećG, Kurzyna M, MroczekE, et al. Database of pulmonary hypertension in the Polish population (BNPPL): design of the registry. Kardiol Pol.2019; 77(10): 972-974, doi: 10.33963/KP.14988, indexed in Pubmed: 31553328.

19. McGoon MD, Benza RL, Escribano-Subias P, et al. Pulmonary arterial hypertension: epidemiology and registries. J Am Coll Cardiol. 2013;62(Suppl 25): D51-D59, doi: 10.1016/j.jacc.2013.10.023, indexed in Pubmed: 24355642.

20. Niklas K, Niklas A, Mularek-Kubzdela T, et al. Prevalence of pulmonary hypertension in patients with systemic sclerosis and mixed connective tissue disease. Medicine (Baltimore). 2018; 97(28): e11437, doi: 10.1097/MD.0000000000011437, indexed in Pubmed: 29995796.

21. Weatherald J, Montani D, Jevnikar $M$, et al. Screening for pulmonary arterial hypertension in systemic sclerosis. Eur Respir Rev. 2019; 28(153): 190023, doi: 10.1183/16000617.0023-2019, indexed in Pubmed: 31366460.

22. Nihtyanova SI, Schreiber BE, Ong VH, et al. Prediction of pulmonary complications and long-term survival in systemic sclerosis. Arthritis Rheumatol. 2014; 66(6): 1625-1635, doi: 10.1002/art.38390, indexed in Pubmed: 24591477.

23. Kanecki K, Goryński $P$, Tarka $P$, et al. Incidence and prevalence of systemic sclerosis (ssc) in Poland - differences between rural and urban regions. Ann Agric Environ Med. 2017; 24(2): 240-244, doi: 10.5604/12321966.1233570, indexed in Pubmed: 28664701.

24. Szczeklik A, Gajewski P. Interna Szczeklika. Medycyna Praktyczna, Kraków 2020.

25. Weatherald J, Boucly A, Launay D, et al. Haemodynamics and serial risk assessment in systemic sclerosis associated pulmonary arterial hypertension. Eur Respir J. 2018; 52(4): 1800678, doi: 10.1183/13993003.00678-2018, indexed in Pubmed: 30209196.

26. Kolstad KD, Li S, Steen V, et al. PHAROS Investigators. Long-term outcomes in systemic sclerosis-associated pulmonary arterial hypertension from the Pulmonary Hypertension Assessment and Recognition of Outcomes in Scleroderma registry (PHAROS). Chest. 2018; 154(4): 862-871, doi: 10.1016/j.chest.2018.05.002, indexed in Pubmed: 29777655.

27. Vonk MC, Vandecasteele E, van Dijk AP. Pulmonary hypertension in connective tissue diseases, new evidence and challenges. Eur J Clin Invest. 2021; 51(4): e13453, doi: 10.1111/eci.13453, indexed in Pubmed: 33216992.

28. Jiang $Y$, Turk MA, Pope JE. Factors associated with pulmonary arterial hypertension (PAH) in systemic sclerosis (SSc). Autoimmun Rev. 2020; 19(9): 102602, doi: 10.1016/j.autrev.2020.102602, indexed in Pubmed: 32659476.
29. Chung L, Liu J, Parsons L, et al. Characterization of connective tissue disease-associated pulmonary arterial hypertension from REVEAL: identifying systemic sclerosis as a unique phenotype. Chest. 2010; 138(6): 1383-1394, doi: 10.1378/chest.10-0260, indexed in Pubmed: 20507945.

30. Tyndall AJ, Bannert B, Vonk M, et al. Causes and risk factors for death in systemic sclerosis: a study from the EULAR Scleroderma Trials and Research (EUSTAR) database. Ann Rheum Dis. 2010; 69(10): 1809-1815, doi: 10.1136/ard.2009.114264, indexed in Pubmed: 20551155.

31. Galiè N, Humbert M, Vachiery JL, et al. 2015 ESC/ERS guidelines for the diagnosis and treatment of pulmonary hypertension: the joint task force for the diagnosis and treatment of pulmonary hypertension of the European Society of Cardiology (ESC) and the European Respiratory Society (ERS): endorsed by: Association for European Paediatric and Congenital Cardiology (AEPC), International Society for Heart and Lung Transplantation (ISHLT). Eur Respir J. 2015; 46(4): 903-975, doi: 10.1183/13993003.010322015, indexed in Pubmed: 26318161.

32. Frost $A$, Badesch D, Gibbs JS, et al. Diagnosis of pulmonary hypertension. Eur Respir J. 2019; 53(1): 1801904, doi: 10.1183/13993003.01904-2018, indexed in Pubmed: 30545972.

33. Young A, Nagaraja V, Basilious $M$, et al. Update of screening and diagnostic modalities for connective tissue disease-associated pulmonary arterial hypertension. Semin Arthritis Rheum. 2019; 48(6): 1059-1067, doi: 10.1016/j.semarthrit.2018.10.010, indexed in Pubmed: 30415942.

34. Schoenfeld SR, Choi HK, Sayre EC, et al. Risk of pulmonary embolism and deep venous thrombosis in systemic sclerosis: a general population-based study. Arthritis Care Res (Hoboken). 2016; 68(2): 246-253, doi: 10.1002/acr.22673, indexed in Pubmed: 26212772.

35. Rudski LG, Lai WW, Afilalo J, et al. Guidelines for the echocardiographic assessment of the right heart in adults: a report from the American Society of Echocardiography endorsed by the European Association of Echocardiography, a registered branch of the European Society of Cardiology, and the Canadian Society of Echocardiography. J Am Soc Echocardiogr. 2010; 23(7): 685-713, quiz 786-788, doi: 10.1016/j.echo.2010.05.010, indexed in Pubmed: 20620859.

36. Kowal-Bielecka O, Fransen J, Avouac J, et al. EUSTAR Coauthors. Update of EULAR recommendations for the treatment of systemic sclerosis. Ann Rheum Dis. 2017; 76(8): 1327-1339, doi: 10.1136/annrheumdis-2016-209909, indexed in Pubmed: 27941129.

37. Montani D, Savale L, Natali D, et al. Long-term response to calcium-channel blockers in non-idiopathic pulmonary arterial hypertension. Eur Heart J. 2010; 31(15): 1898-1907, doi: 10.1093/eurheartj/ehq170, indexed in Pubmed: 20543192

38. Olsson K, Delcroix $M$, Ghofrani $H$, et al. Anticoagulation and survival in pulmonary arterial hypertension. Circulation. 2014; 129(1): 57-65, doi: 10.1161/circulationaha.113.004526.

39. Benza RL, Gomberg-Maitland M, Elliott CG, et al. Predicting survival in patients with pulmonary arterial hypertension: the REVEAL risk score calculator 2.0 and comparison with ESC/ERS-based risk assessment strategies. Chest. 2019; 156(2):323-337, doi: 10.1016/j.chest.2019.02.004, indexed in Pubmed: 30772387.

40. Kylhammar D, Kjellström B, Hjalmarsson C, et al. A comprehensive risk stratification at early follow-up determines prognosis in pulmonary arterial hypertension. Eur Heart J. 2018; 39(47): 4175-4181, doi: 10.1093/eurheartj/ehx257, indexed in Pubmed: 28575277.

41. Humbert $M$, Sitbon $O$, Chaouat $A$, et al. Pulmonary arterial hypertension in France: results from a national registry. Am J Respir Crit Care Med. 2006; 173(9): 1023-1030, doi: 10.1164/rccm.200510-16680C, indexed in Pubmed: 16456139.

42. Hoeper MM, Kramer T, Pan Z, et al. Mortality in pulmonary arterial hypertension: prediction by the 2015 European pulmonary hypertension guidelines risk stratification model. Eur Respir J. 2017; 50(2): 1700740, doi: 10.1183/13993003.00740-2017, indexed in Pubmed: 28775047.

43. Hachulla E, Launay D, Yaici A, et al. French PAH-SSc Network. Pulmonary arterial hypertension associated with systemic sclerosis in patients with functional class II dyspnoea: mild symptoms but severe outcome. Rheumatology (Oxford). 2010; 49(5): 940-944, doi: 10.1093/rheumatology/kep449, indexed in Pubmed: 20144930.

44. Morrisroe K, Stevens W, Huq M, et al. Australian Scleroderma Interest Group (ASIG). Survival and quality of life in incident systemic sclerosis-re- 
lated pulmonary arterial hypertension. Arthritis Res Ther. 2017; 19(1): 122, doi: 10.1186/s13075-017-1341-x, indexed in Pubmed: 28576149.

45. Galiè N, Channick RN, Frantz RP, et al. Risk stratification and medical therapy of pulmonary arterial hypertension. Eur Respir J. 2019;53(1): 1801889, doi: 10.1183/13993003.01889-2018, indexed in Pubmed: 30545971.

46. Gadre SK, Minai OA, Wang XF, et al. Lung or heart-lung transplant in pulmonary arterial hypertension: what is the impact of systemic sclerosis? Exp Clin Transplant. 2017; 15(6): 676-684, doi: 10.6002/ect.2016.0209, indexed in Pubmed: 28540841.

47. Shah RJ, Boin F. Lung transplantation in patients with systemic sclerosis. Curr Rheumatol Rep. 2017; 19(5):23, doi: 10.1007/s11926-017-0650-Z, indexed in Pubmed: 28386760.

48. Lefèvre $G$, Dauchet $L$, Hachulla $E$, et al. Survival and prognostic factors in systemic sclerosis-associated pulmonary hypertension: a systematic review and meta-analysis. Arthritis Rheum. 2013; 65(9): 2412-2423, doi: 10.1002/art.38029, indexed in Pubmed: 23740572.

49. Launay D, Sitbon $O$, Hachulla $E$, et al. Survival in systemic sclerosis-associated pulmonary arterial hypertension in the modern management era. Ann Rheum Dis. 2013; 72(12): 1940-1946, doi: 10.1136/annrheumdis-2012-202489, indexed in Pubmed: 23178295.

50. Khanna D, Zhao C, Saggar R, et al. Long-Term outcomes in patients with connective tissue disease-associated pulmonary arterial hypertension in the modern treatment era: meta-analyses of randomized, controlled trials and observational registries. Arthritis Rheumatol. 2021; 73(5): 837-847, doi: 10.1002/art.41669, indexed in Pubmed: 33538058.

51. Badesch DB, Tapson VF, McGoon MD, et al. Continuous intravenous epoprostenol for pulmonary hypertension due to the scleroderma spectrum of disease. A randomized, controlled trial. Ann Intern Med. 2000; 132(6): 425-434, doi: 10.7326/0003-4819-132-6-200003210-00002, indexed in Pubmed: 10733441.

52. Almaaitah S, Highland KB, Tonelli AR. Management of pulmonary arterial hypertension in patients with systemic sclerosis. Integr Blood Press Control. 2020; 13: 15-29, doi: 10.2147/IBPC.S232038, indexed in Pubmed: 32280271.

53. Sobanski V, Launay D, Hachulla E, et al. Current approaches to the treatment of systemic-sclerosis-associated pulmonary arterial hypertension (SSc-PAH). Curr Rheumatol Rep. 2016; 18(2): 10, doi: 10.1007/s11926-0150560-x, indexed in Pubmed: 26841964.

54. Pulido T, Adzerikho I, Channick RN, et al. SERAPHIN Investigators. Macitentan and morbidity and mortality in pulmonary arterial hypertension. $\mathrm{N}$ Engl J Med. 2013;369(9):809-818, doi: 10.1056/NEJMoa1213917, indexed in Pubmed: 23984728.
55. Gaine S, Chin K, Coghlan G, et al. Selexipag for the treatment of connective tissue disease-associated pulmonary arterial hypertension. Eur Respir J. 2017; 50(2): 1602493, doi: 10.1183/13993003.02493-2016, indexed in Pubmed: 28818881.

56. Coghlan J, Galiè N, Barberà J, et al. Initial combination therapy with ambrisentan and tadalafil in connective tissue disease-associated pulmonary arterial hypertension (CTD-PAH): subgroup analysis from the AMBITION trial. Annals of the Rheumatic Diseases. 2016; 76(7): 1219-1227, doi: 10.1136/annrheumdis-2016-210236.

57. Zizzo G, De Santis M, Ferraccioli GF. Mycophenolic acid in rheumatology: mechanisms of action and severe adverse events. Reumatismo. 2010; 62(2): 91-100, doi: 10.4081/reumatismo.2010.91, indexed in Pubmed: 20657885.

58. Nawata M, Nagayasu A, Fujita Y, et al. Severe pulmonary arterial hypertension and interstitial pneumonia related to systemic lupus erythematosus successfully treated with mycophenolate mofetil: a novel case report. Lupus. 2020; 29(14): 1955-1960, doi: 10.1177/0961203320958055, indexed in Pubmed: 32914681.

59. Donate PB, Cunha TM, Verri WA, et al. Bosentan, an endothelin receptor antagonist, ameliorates collagen-induced arthritis: the role of TNF- $\alpha$ in the induction of endothelin system genes. Inflamm Res. 2012; 61(4): 337-348, doi: 10.1007/s00011-011-0415-5, indexed in Pubmed: 22249931.

60. Coirier V, Lescoat A, Chabanne C, et al. Pulmonary arterial hypertension in four patients treated by leflunomide. Joint Bone Spine. 2018; 85(6): 761763, doi: 10.1016/j.jbspin.2017.12.014, indexed in Pubmed: 29329993.

61. McGee M, Whitehead N, Martin J, et al. Drug-associated pulmonary arterial hypertension. Clin Toxicol (Phila). 2018; 56(9): 801-809, doi: 10.1080/15563650.2018.1447119, indexed in Pubmed: 29508628.

62. Quah Ed, Amoasii C, Mudawi T, et al. Systematic literature review investigating whether methotrexate causes chronic pulmonary fibrosis. Future Healthc J. 2019; 6(Suppl 2): 4, doi: 10.7861/futurehosp.6-2s-s4, indexed in Pubmed: 31572905.

63. Grossi O, Horeau-Langlard D, Agard C, et al. Low-dose methotrexate in $\mathrm{PAH}$ related to T-cell large granular lymphocyte leukaemia. Eur Respir J. 2012; 39(2): 493-494, doi: 10.1183/09031936.00014811, indexed in Pubmed: 22298613.

64. Dwyer N, Jones $G$, Kilpatrick D. Severe hepatotoxicity in a patient on bosentan upon addition of methotrexate: reversible with resumption of methotrexate without bosentan. J Clin Rheumatol. 2009; 15(2): 88-89, doi: 10.1097/RHU.0b013e31819bc71f, indexed in Pubmed: 19265355 . 